\title{
Interactive effect between ATPase-related genes and early-life tobacco smoke exposure on bronchial hyper-responsiveness detected in asthma-ascertained families
}

\author{
Marie-Hélène Dizier, ${ }^{1,2}$ Patricia Margaritte-Jeannin, ${ }^{1,2}$ Lucile Pain, ${ }^{3}$ Chloé Sarnowski, ${ }^{1,2}$ \\ Myriam Brossard, ${ }^{1,2}$ Hamida Mohamdi, ${ }^{1,2}$ Nolwenn Lavielle, ${ }^{1,2}$ \\ Marie-Claude C Babron, ${ }^{1,2}$ Jocelyne Just, ${ }^{4}$ Mark Lathrop, ${ }^{5}$ Catherine Laprise, ${ }^{3}$ \\ Emmanuelle Bouzigon, ${ }^{1,2}$ Florence Demenais, ${ }^{1,2}$ Rachel Nadif ${ }^{6,7}$
}

\begin{abstract}
- Additional material is
published online only. To view please visit the journal online (http://dx.doi.org/10.1136/ thoraxjn-2018-211797).
\end{abstract}

For numbered affiliations see end of article.

Correspondence to Marie-Hélène Dizier, UMR946, INSERM/Université ParisDiderot, Paris F-75010, France; marie-helene.dizier@inserm.fr

$\mathrm{CL}$ and $\mathrm{EB}$ contributed equally. $\mathrm{FD}$ and $\mathrm{RN}$ contributed equally.

Received 15 March 2018 Revised 21 June 2018 Accepted 20 August 2018 Published Online First 3 October 2018

\section{Linked}

- http://dx.doi.org/10.1136/ thoraxjnl-2018-212511

\section{Check for updates}

(C) Author(s) (or their employer(s)) 2019. No commercial re-use. See rights and permissions. Published by BMJ.

\footnotetext{
To cite: Dizier $\mathrm{M}-\mathrm{H}$,

Margaritte-Jeannin P, Pain L, et al. Thorax

2019;74:254-260.
}

\section{ABSTRACT \\ Background A positional cloning study of bronchial hyper-responsiveness (BHR) at the 17p11 locus in the French Epidemiological study on the Genetics and Environment of Asthma (EGEA) families showed significant interaction between early-life environmental tobacco smoke (ETS) exposure and genetic variants located in DNAH9. This gene encodes the heavy chain subunit of axonemal dynein, which is involved with ATP in the motile cilia function. \\ Our goal was to identify genetic variants at other genes interacting with ETS in BHR by investigating all genes belonging to the 'ATP-binding' and 'ATPase activity' pathways which include DNAH9, are targets of cigarette smoke and play a crucial role in the airway inflammation. Methods Family-based interaction tests between ETS- exposed and unexposed BHR siblings were conducted in 388 EGEA families. Twenty single-nucleotide polymorphisms (SNP) showing interaction signals $\left(p \leq 5.10^{-3}\right)$ were tested in the 253 Saguenay-Lac-Saint- Jean (SLSJ) families. \\ Results One of these SNPs was significantly replicated for interaction with ETS in SLSJ families ( $p=0.003$ ). \\ Key messages \\ What is the key question? \\ - Could genes belonging to ATP-related pathways interact with exposure to early- life tobacco smoke exposure on bronchial hyper-responsiveness? \\ What is the bottom line? \\ - Gene $\times$ environment interaction analyses with ATP-related genes allowed to identify promising candidate genes, ATP8A1 and ABCA1, interacting with early-life tobacco smoke exposure in bronchial hyper-responsiveness susceptibility. \\ Why read on? \\ - The present study highlights that gene $x$ environment interaction analyses under a pathway-based strategy can greatly contribute to the identification of novel genes involved in complex disease as bronchial hyper-responsiveness.} Another SNP reached the significance threshold after correction for multiple testing in the combined analysis of the two samples $\left(p=10^{-5}\right)$. Results were confirmed using both a robust log-linear test and a gene-based interaction test.

Conclusion The SNPs showing interaction with ETS belong to the ATP8A1 and ABCA1 genes, which play a role in the maintenance of asymmetry and homeostasis of lung membrane lipids.

\section{INTRODUCTION}

Bronchial hyper-responsiveness (BHR) is both a feature and an important risk factor for asthma. ${ }^{1}$ The susceptibility genes for asthma and BHR, ${ }^{2}$ identified to date, account for a relatively small proportion of the genetic component of these phenotypes. ${ }^{3}$ As asthma and BHR are complex diseases which result from both genetic and environmental factors, the effect of genetic factors may be missed if they are tested individually, that is, by ignoring gene by environment $(\mathrm{G} \times \mathrm{E})$ interactions. Furthermore, taking into account the biological function shared by genes or pathways they are involved in may help discovering new genes. ${ }^{4}$

Maternal smoking during pregnancy and earlylife environmental tobacco smoke (ETS) exposure are well-known risk factors for asthma and BHR. ${ }^{5}$ Gene $\times$ ETS interaction underlying susceptibility to asthma and asthma-related phenotypes have been evidenced by positional cloning studies which detected protocadherin 1 (PCDH1) and ADAM metallopeptidase domain 33 (ADAM33) genes ${ }^{6-8}$ by association studies with candidate genes including $\beta 2$-adrenergic receptor (ADRB2), ${ }^{9}$ and by interaction analysis with genetic variants at the $17 \mathrm{q} 12-21$ locus discovered by the first asthma genome-wide association studies (GWAS). ${ }^{10}{ }^{11}$ More recently, a meta-analysis of genome-wide interaction studies (GEWIS) for childhood asthma $^{12}$ suggested interaction between ETS 
exposure and Parkin coregulated $(P A C R G)$ - a gene having a role in motile cilia function.

In the French Epidemiological study on the Genetics and Environment of Asthma (EGEA) families, we previously performed a positional cloning study in the $17 \mathrm{p} 11$ region that showed interactive effect between ETS and Dynein, Axonemal, Heavy Chain 9 (DNAH9 $)^{1314}$ genetic variant on BHR. This gene encodes the heavy chain subunit of axonemal dynein, a component responsible for cilia mobility. Interestingly, a recent study of atopy, another asthma-related phenotype, showed significant interaction between DNAH5, a gene of the same family as DNAH9, and ADGRV1 (adhesion G protein-coupled receptor V1), both genes being involved in ciliary function. ${ }^{15}$ Overall, these findings suggest that ciliary dysfunction may represent a novel mechanism underlying asthma-related phenotypes.

The heavy chain subunit of axonemal dynein contains all of the elements that are needed to convert the energy into movement through a process in which dynein, ATP binding and ATP hydrolysis are involved. ${ }^{16-18}$ Interestingly, in patients with asthma, ATP was shown to be accumulated in the airways and to trigger BHR, suggesting an important role played by ATP in the airway inflammation. ${ }^{19}$ Moreover, ATP-binding cassette (ABC) transporters were implicated in pulmonary lipid homeostasis and inflammation, indicating a crucial and protective role in lung. ${ }^{20}$

Smoking and exposure to cigarette smoke have been shown to affect the number and function of human bronchial cilia, ${ }^{18} 21$ while a significant loss of $\mathrm{Na}$, K-ATPase activity was observed in human lung cell lines exposed to cigarette smoke ${ }^{22}$ and in platelet membrane in cigarette smokers compared with controls. ${ }^{23}$

In the present study, we hypothesised that genes belonging to 'ATPase activity' and 'ATP binding' pathways, the two ATP-related pathways that include DNAH9, may also interact with exposure to ETS in BHR. We tested for interaction all genes of these two pathways using the discovery sample of 388 French EGEA families, ascertained through asthmatic probands. We first applied Family-Based Association Test (FBAT) ${ }^{24}$ homogeneity test between exposed and unexposed BHR siblings to detect interactions for single-nucleotide polymorphisms (SNP) located in the genes belonging to the two pathways. Replication of results was sought in an independent sample of 253 French-Canadian asthma-ascertained families. We also validated our results by using another $\mathrm{SNP} \times \mathrm{E}$ interaction test based on log-linear modelling case-parent triads, ${ }^{25}$ and finally by gene-based interaction analysis.

\section{MATERIALS AND METHODS Discovery sample}

The EGEA study and inclusion criteria have been described in detail previously. ${ }^{26}$ The EGEA family sample consisted of 388 French nuclear families that included 253 families ascertained through offspring with asthma (one offspring proband in $90 \%$ of families and two offspring probands in the remainder) and 135 families ascertained through one parent with asthma.

The BHR phenotype was defined according to the results of the methacholine bronchial challenge test, as done previously. ${ }^{1314}$ Participants who had a fall in their baseline FEV $_{1} \geq 20 \%$ at $\leq 4 \mathrm{mg} / \mathrm{mL}$ of methacholine (PD20) had BHR while participants who did not show a fall in $\mathrm{FEV}_{1}$ did not have BHR. The protocol of the methacholine challenge test has been described in detail elsewhere. ${ }^{26}$

The ETS exposure in early childhood was defined, as previously ${ }^{101314}$ through questionnaires: (1) for an adult, by a positive answer to the question: 'Did your mother or your father smoke during your early-childhood?' and (2) for a child, by a positive answer to the question asked to the child's mother (or father): 'Did you or the father (or the mother) of your child smoke when your child was less than 2 years old?' We did not use information on in utero exposure to tobacco smoke since all mothers who smoked during pregnancy continued to smoke during the early childhood of their offspring.

\section{Replication study}

The Saguenay-Lac-Saint-Jean (SLSJ) asthma study comprised 253 French-Canadian multigenerational families ascertained through two probands with asthma. ${ }^{27}$ Inclusion criteria of probands have been described previously. ${ }^{27}$

The BHR (PD20) phenotype and ETS exposure were defined in SLSJ in an identical manner as in the EGEA study.

\section{Genotyping}

The EGEA subjects were genotyped using Illumina 610 Quad array (Illumina, San Diego, CA) at the Centre National de Génotypage (CNG, Evry, France), as part of the European Gabriel consortium asthma GWAS. ${ }^{28}$ Stringent quality control criteria, as detailed previously, ${ }^{28}$ were used to select both individuals and genotyped SNPs for analysis. For this study, we selected from the Gene Ontology (GO) database (http://amigo.geneontology. org/) 296 genes belonging to both molecular functions 'ATPase binding' (GO: 0005524) and 'ATPase activity' (GO: 0016887) and the corresponding 4252 SNPs located within these genes (see online supplementary table S1).

The SLSJ sample was also genotyped at CNG using the Illumina 610 Quad array. The same quality control criteria for individuals and SNPs as those used for EGEA, were applied to this data set.

\section{Statistical analysis}

$\mathrm{G} \times \mathrm{E}$ interaction analysis using FBAT homogeneity test.

\section{Analysis of the EGEA discovery sample}

Analyses were conducted using the FBAT approach, ${ }^{24}$ which tests for association in presence of linkage. We assumed an additive genetic model and used the option for an empirical estimator of the variance, ${ }^{29}$ which makes the association test robust to the dependency between siblings and allows use of all siblings in a family. FBAT was applied separately to ETS-exposed and unexposed siblings. We searched for $\mathrm{SNP} \times \mathrm{ETS}$ interaction by testing homogeneity of FBAT association results between ETS exposed and unexposed..$^{30}$ Note that after exclusion of SNPs leading to insufficient sample size $(<30)$ of informative families for FBAT analyses in the EGEA sample, only 4112 SNPs belonging to only 266 genes were analysed.

\section{Replication analysis with the SLSJ sample}

SNPs showing interaction signals $\left(\mathrm{p} \leq 5 \times 10^{-3}\right)$ in the EGEA sample were followed up in the SLSJ sample. The arbitrary threshold of $5.10^{-3}$ was chosen to obtain both a strong indication of association and a reasonable number of SNPs (here 20, see the Results section) tested in the replication data set. For replication study of these SNPs detected in EGEA, both analysis in SLSJ and combined analysis in EGEA and SLSJ were conducted.

First, analyses were conducted in SLSJ and results were declared as significant if they meet the Bonferroni corrected significance $\mathrm{p}$ threshold applied to the Meff (effective number of independent tests after discarding dependence due to linkage disequilibrium (LD) between the SNPs) ${ }^{31}$ calculated from the 20 
SNPs tested in SLSJ. The Meff was estimated to 15 and thus the significance $\mathrm{p}$ threshold equal to $3 \cdot 10^{-3}$.

Second, combined FBAT analysis of the EGEA and SLSJ samples was conducted separately in ETS-exposed and unexposed siblings using the Stouffer's Z-score method, and homogeneity test was applied between exposed and unexposed siblings to the combined results. The results of this combined analysis are not independent from the results obtained in EGEA. We thus declared results as significant if they meet the significance $\mathrm{p}$ threshold $\left(\mathrm{p}=2.10^{-5}\right)$, calculated after correction for multiple tests by the Bonferroni correction applied to the Meff (2500) estimated from the total number of SNPs tested in EGEA.

\section{Validation analysis using Umbach and Weinberg method}

In order to validate the significant interactions found with the FBAT homogeneity test, we applied the log-linear modelling approach for testing interaction in triads (case and parents), as proposed by Umbach and Weinberg (UW), ${ }^{25}$ to the pooled sample of EGEA and SLSJ. This approach allows adjusting on the genotypic parental mating of each sibling and thus avoids bias due to population stratification. A different distribution of parental genotypic mating between exposed and unexposed siblings, due to population stratification, may lead to different transmission probabilities in the two groups and consequently to false detection of interaction. FBAT is less robust because it only adjusts for the genotypic parental distribution within the exposed and unexposed groups of siblings. However, the UW method is less powerful than FBAT because it can be applied to only one sib per family. The log-linear analysis was conducted using the youngest siblings for whom the information on ETS exposure was the closest in time with respect to BHR occurrence and thus the less influenced by a potential recall bias. The analysis was also performed by considering the oldest siblings, but similar results were obtained and are thus not presented.

As for FBAT analysis, all UW analyses assumed an additive genetic model and the same correction for multiple testing was applied, that is, Bonferroni correction applied to the Meff of 2500 .

\section{Gene-based analysis}

For each of the 266 genes, interactions with ETS exposure in BHR were also investigated at the gene level by using the versatile gene-based test (Versatile Gene-based Association Study). ${ }^{32}$ The gene-based statistic was defined as the best SNP test statistic (or min $\mathrm{p}$ value) using the results of FBAT homogeneity tests in the combined analysis of EGEA and SLSJ samples. Empirical $\mathrm{p}$ value of the gene-based statistic was computed through Monte Carlo simulations using the LD pattern of HapMap CEU reference sample. The empirical $p$ values were adjusted for multiple testing using the Bonferroni correction (significance $p$ threshold $=0.05 / 266=2.10^{-4}$ ).

Expression quantitative trait loci analysis, functional annotation and chemical-gene/protein interactions

We investigated whether the SNPs (or their proxies, $\mathrm{r}^{2} \geq 0.8$ ) found to interact with ETS were cis-expression quantitative trait loci (cis-eQTLs). We used the GTEx browser (http://www. gtexportal.org/home/) ${ }^{33}$ that includes e-QTL data from many tissues. Functional annotations of these SNPs (or proxies) were done using the HaploReg tool (http:/www.broadinstitute.org/ mammals/haploreg/haploreg.php). HaploReg annotates SNPs in terms of colocalisation with regulatory elements, such as promoter and enhancer marks, DNase I hypersensitivity sites,
Table 1 Phenotypic features of genotyped siblings having BHR in EGEA and SLSJ asthma-ascertained families

\begin{tabular}{lcc}
\hline & EGEA & \multicolumn{1}{l}{ SLSJ } \\
\hline Siblings $(\mathrm{n})$ & \multicolumn{1}{c}{104} & \multicolumn{1}{c}{145} \\
\hline Age (years), mean (SD) & $16.1(8.1)$ & $20.3(10.3)$ \\
\hline Sex, $\mathrm{n}(\%)$ women & $132(43.4)$ & $76(52.4)$ \\
\hline Asthma, $\mathrm{n}(\%)$ & $181(59.5)$ & $138(95.2)$ \\
\hline Age at asthma onset (years), mean (SD) & $7.4(7.7)$ & $9.4(9.3)$ \\
\hline Allergic sensitisation ${ }^{*}, \mathrm{n}(\%)$ & $228(76.0)$ & $121(85.8)$ \\
\hline ETS exposure, $\mathrm{n}(\%)$ & $176(57.9)$ & $93(64.1)$ \\
\hline
\end{tabular}

${ }^{*}$ Allergic sensitisation: a positive response of skin prick test to at least one allergen. BHR, bronchial hyper-responsiveness; EGEA, Epidemiological study on the Genetics and Environment of Asthma; ETS, environmental tobacco smoke; SLSJ, SaguenayLac-Saint-Jean.

and transcription factor (TF) and protein-binding sites, based on Roadmap Epigenomics data and Encyclopedia of DNA Elements data.

Furthermore, curated (chemical-gene interactions|chemicaldisease (gene-disease) data were retrieved from the Comparative Toxicogenomics Database (CTD), ${ }^{34}$ MDI Biological Laboratory, Salisbury Cove, Maine, and NC State University, Raleigh, North Carolina. World Wide Web (URL: http://ctdbase.org/) (May 2018). CTD is a robust, publicly available database that aims to advance understanding about how environmental exposures affect human health. It provides manually curated information about chemical-gene/protein interactions, chemical-disease and gene-disease relationships.

\section{RESULTS}

\section{Data description}

The characteristics of genotyped siblings having BHR in EGEA and SLSJ families are shown in table 1.

Three hundred and four siblings (from 189 families) had BHR in EGEA and 145 (from 120 families) in SLSJ. They were younger in EGEA than in SLSJ with respective mean ages equal to 16.1 and 20.3 years $\left(\mathrm{p}<10^{-4}\right)$. The proportion of siblings with allergic sensitisation was similar in the two data sets $(76 \%$ in EGEA and 86\% in SLSJ), while the proportion of asthmatics was higher in SLSJ $(95 \%)$ than in EGEA $(60 \%)\left(\mathrm{p}<10^{-4}\right)$. The proportion of female was similar in the two data sets $(43 \%$ in EGEA and 52\% in SLSJ). The mean age at onset of asthma was slightly lower in EGEA (7.4) than in SLSJ (9.4) $(p=0.05)$. Finally, the proportion of exposed siblings was similar in EGEA and in SLSJ (58\% vs 64\% respectively).

\section{Analysis of genexETS interactions using FBAT homogeneity test}

The results in the EGEA, SLSJ and combined samples are shown in table 2 (for more details see online supplementary table S2).

FBAT homogeneity test in EGEA detected 20 SNPs (at the level of $\mathrm{p} \leq 5.10^{-3}$ ), for which replication study was then conducted. The analysis in SLSJ detected a significant association $\left(\mathrm{p}=3.10^{-3}\right)$ with one of these SNPs, rs2253304, which is located in ABCA1 intron. The combined analysis of the two EGEA and SLSJ samples detected another SNP, rs17448506, which is located in ATP8A1 intron, and reached the significance threshold for interaction with ETS $\left(p=10^{-5}\right)$. The SNP rs2253304 was also the second top signal in the combined analysis $\left(p=6 \cdot 10^{-5}\right)$.

At both SNPs, there was a 'Flip-Flop' interaction effect (ie, an inverse effect depending on exposure): the $\mathrm{C}$ allele (vs $\mathrm{T}$ allele) 
Table 2 Results of FBAT homogeneity test in the EGEA and SLSJ samples for SNPs detected in EGEA with $p \leq 5.10^{-3}$

\begin{tabular}{|c|c|c|c|c|c|c|c|c|}
\hline & & & & & & EGEA & SLSJ & EGEA+SLSJ‡ \\
\hline Chromosome & SNP & Gene & Location & Position* (kb) & MAFt & $P$ values & $P$ values & $P$ values \\
\hline 1 & rs10924249 & KIF26B & flanking_3UTR & 243837 & 0.18 & 0.004 & 0.302 & 0.059 \\
\hline 2 & rs6736802 & KIF5C & flanking_5UTR & 149566 & 0.43 & 0.002 & 0.320 & 0.056 \\
\hline 2 & rs6435220 & KIF5C & flanking_5UTR & 149569 & 0.31 & 0.003 & 0.659 & 0.032 \\
\hline 4 & rs1460354 & ATP8A1 & Intron & 42266 & 0.22 & 0.001 & 0.115 & $6.0 \mathrm{E}-04$ \\
\hline 4 & rs13124088 & ATP8A1 & Intron & 42280 & 0.20 & 0.005 & 0.227 & 0.004 \\
\hline 4 & rs17448506 & ATP8A1 & Intron & 42343 & 0.27 & 1.7E-05 & 0.133 & $1.2 \mathrm{E}-05$ \\
\hline 6 & rs160666 & WRNIP1 & flanking_3UTR & 2719 & 0.32 & 0.003 & 0.398 & 0.041 \\
\hline 8 & rs2279444 & KIF13B & Intron & 29053 & 0.15 & 0.005 & 0.400 & 0.006 \\
\hline 9 & rs2253304 & ABCA1 & Intron & 106658 & 0.27 & 0.004 & 0.003 & $6.1 \mathrm{E}-05$ \\
\hline 9 & rs2253182 & $\mathrm{ABCA} 1$ & Intron & 106659 & 0.27 & 0.004 & 0.005 & $9.2 \mathrm{E}-05$ \\
\hline 9 & rs2253175 & $\mathrm{ABCA} 1$ & Intron & 106660 & 0.27 & 0.004 & 0.004 & $7.2 \mathrm{E}-05$ \\
\hline 9 & rs2253174 & ABCA1 & Intron & 106660 & 0.27 & 0.004 & 0.004 & 7.2E-05 \\
\hline 9 & rs2230805 & ABCA1 & Coding & 106663 & 0.25 & 0.005 & 0.017 & $2.0 \mathrm{E}-04$ \\
\hline 11 & rs762667 & MY07A & Coding & 76546 & 0.38 & 0.002 & 0.446 & 0.003 \\
\hline 16 & rs2914819 & ATP2C2 & Intron & 83026 & 0.19 & 0.003 & 0.353 & 0.0018 \\
\hline 17 & rs7225157 & DNAH9§ & Intron & 11621 & 0.17 & $8.1 \mathrm{E}-04$ & 0.038 & $6.8 \mathrm{E}-05$ \\
\hline 18 & rs12458154 & ATP9B & Intron & 75187 & 0.28 & 0.002 & 0.551 & 0.0047 \\
\hline 20 & rs6067867 & ATP9A & Intron & 49698 & 0.46 & 0.005 & 0.376 & 0.0056 \\
\hline 20 & rs6067892 & ATP9A & Intron & 49731 & 0.47 & 0.002 & 0.410 & 0.0036 \\
\hline 20 & rs1475670 & ATP9A & Intron & 49777 & 0.50 & 0.004 & 0.058 & 7.0E-04 \\
\hline
\end{tabular}

Significant results are in bold.

*SNP position in kilobase (dbSNP, build 37.1).

†Minor Allele Frequency estimated in EGEA.

¥Combined analysis of the EGEA and SLSJ samples using the Stouffer's Z-score method.

$\S$ Previously detected by our positional cloning. ${ }^{14}$

EGEA, Epidemiological study on the Genetics and Environment of Asthma; FBAT, Family-Based Association Test; SLSJ, Saguenay-Lac-Saint-Jean; SNP, single-nucleotide polymorphism.

of rs17448506 was positively associated with BHR in ETS-exposed siblings and negatively in ETS-unexposed siblings, while G allele (vs A allele) of rs2253304 was positively associated with BHR in ETS-exposed siblings and negatively in ETS-unexposed siblings.

\section{Validation analysis using UW method}

For the two SNPs retained by the analyses based on FBAT homogeneity test (rs17448506 and rs2253304), results of UW analysis in the pooled EGEA and SLSJ samples are presented in table 3.

Both SNPs showed quite strong signals of interaction $\left(\mathrm{p} \leq 10^{-3}\right)$ with the UW method, although they did not reach the significance threshold of $2 \times 10^{-5}$.

\section{Gene-based analysis}

Results by the gene-based test using the combined results of EGEA and SLSJ were given for all 266 genes in online supplementary table S3. ATP8A1 and ABCA1 were the first and third top genes, respectively, interacting with ETS exposure in BHR that were detected $\left(\mathrm{p}=3.10^{-4}\right.$ and $\mathrm{p}=3.10^{-3}$, respectively). Only the $\mathrm{p}$ value for ATP8A1 was close to the significance threshold of $2.10^{-4}$ adjusted for multiple testing. The second top gene was $A T P 9 B$ and the fourth top gene was DNAH9.

\section{eQTL, functional annotations and chemical-gene/protein interactions}

No eQTL was found among the SNPs (or proxies) interacting with ETS at ATP8A1 and ABCA1 loci. Using the functional annotation tool HaploReg-v4.1, we found that both SNPs map to enhancer and promoter histone marks and that rs2253304 and its proxies map to DNase hypersensitivity sites, notably in fetal lung fibroblast cell line, lung carcinoma cell line and lung fibroblast primary cells. They also map to binding sites of many TFs including the redox-sensitive nuclear factor (NF)-kappaB $(\mathrm{NF}-\kappa \mathrm{B})$ for rs17448506 and the histone deacetylase 2, activator protein 1, Smad and STAT for rs2253304 and proxies.

Table 3 Results with UW in the pooled sample of EGEA and SLSJ for SNPs detected by FBAT homogeneity test

\begin{tabular}{llllcll}
\hline Chromosome & SNP & Gene & Location & Position* $(\mathbf{k b})$ & MAF & P values \\
\hline 4 & rs17448506 & ATP8A1 & Intron & 42343 & 0.27 & $9.0 \mathrm{E}-04$ \\
9 & rs2253304 & ABCA1 & Intron & 106658 & 0.27 & $5.0 \mathrm{E}-04$ \\
\hline
\end{tabular}

\footnotetext{
*SNP position in kilobase (dbSNP, build 37.1).
}

EGEA, Epidemiological study on the Genetics and Environment of Asthma; FBAT, Family-Based Association Test; MAF, Minor Allele Frequancy; SLSJ, Saguenay-Lac-Saint-Jean; SNP, single-nucleotide polymorphism; UW, Umbach and Weinberg. 
Further, from the CTD, we found that tobacco smoke pollution and soot have been reported to modify the expression of ATP8A1 and ABCA1 mRNA (see online supplementary table S4). We also found that air pollutant exposures known to contain compounds with irritant properties such as in tobacco smoke modified the expression of ABCA1 (see online supplementary table S4).

\section{DISCUSSION}

This study identified genetic variants at two novel loci, in chromosomes 4 and 9, interacting with ETS exposure in BHR. After a selection of SNPs showing signal of interaction with ETS in EGEA, interaction was significantly replicated in SLSJ for a first SNP intronic to $A B C A 1$ gene. Significant interaction with ETS was detected for a second SNP intronic to ATP8A1 gene in the combined analysis of EGEA and SLSJ samples. Furthermore, in the gene-based analysis, $A T P 8 A 1$ and $A B C A 1$ were among the three top genes interacting with ETS exposure, this interaction being very close to the significance level for ATP8A1.

Most of previous interaction studies of genetic variants with ETS on BHR or asthma risk had difficulties to show significant interaction and/or replication in independent samples. ${ }^{6} 1235$ Indeed, replication of $\mathrm{G} \times \mathrm{E}$ interaction is much more difficult to achieve than replication of single SNP association. It is well recognised that interaction tests have low power. Moreover, replication of interaction is affected by heterogeneity in the outcome and in exposure definition of the participating studies. The distribution of exposure may also differ across populations and therefore change the potential to identify the interaction. It is well known that ETS is influenced by socioeconomic position and generation effect. Tobacco use seems to be almost universally more prevalent in low socioeconomic groups than in high socioeconomic groups. ${ }^{36}$ Over the last 10 years, the prevalence of ETS exposure at home among children and the percentage of children whose parents smoke have declined in several industrialised countries. ${ }^{37}$ Difference in the distribution of ETS may thus result in different relationships among the gene, environment and disease. It was difficult to find replication samples that showed consistent definitions of BHR and ETS exposure and similar distribution of ETS exposure with those of the EGEA discovery sample. Only one replication sample from the SLSJ study showed similarities with EGEA in terms of ascertainment through asthmatic subjects, definition of both BHR and ETS, distribution of ETS and genotype information available in parents and siblings. To keep reasonable the number of tests and then limit the problem of low power of interaction test, we examined only SNPs located within gene boundaries. Even if SNPs lying at some distance upstream and downstream from the gene are often considered, the choice of that distance is not obvious.

Nevertheless, we were able to identify two SNPs, with significant evidence for interaction with ETS. These results were confirmed by the UW approach, which is more robust although less powerful than FBAT as described in the Methods section. Our study relies on an original strategy to select and enlarge a list of candidate genes. Supported by biological knowledge, we think our pathway selection approach allows a good trade-off between GEWIS and candidate gene approaches, and offers the possibility to identify new genes as we previously showed. ${ }^{4} \mathrm{We}$ cannot exclude that our selection may lose a number of relevant genes that are not targeted by our analysis. In particular, we choose the stringent option to investigate genes, which similar to DNAH9, belong simultaneously to the two ATP-related pathways. We thus used the intersection and not the union of these two pathways. The advantage of this strategy was to limit the number of SNPs to be tested, leading to a reduction of the multiple testing burden and to a gain of power. Furthermore, after the analysis in the discovery sample (EGEA), we used two different replication analyses of top EGEA results: first analysis in the SLSJ sample, and then a combined analysis in the two samples (EGEA and SLSJ). Although these two types of analyses are not independent (indeed combined analysis of EGEA and SLSJ included SLSJ results), they led to detect two different genes that appear both interesting. Note that the DNAH9 gene evidenced by our previous positional cloning study ${ }^{14}$ was also detected in the present study, ranked as the third top SNP and as the fourth top gene, although results did not reach significance.

To our knowledge, none of our findings have been previously reported by published GWAS (GWAS-Catalogue of Published Genome-Wide Association Studies; http://genome. gov/gwastudies), or by GEWIS for asthma, BHR or lung function. Although a few $\mathrm{G} \times \mathrm{ETS}$ interaction studies ${ }^{16}{ }^{18}$ have been published for BHR to date, neither the ATP8A1 nor the ABCA1 gene has been mentioned.

The ATP8A1 gene codes for a putative aminophospholipid transporting enzyme which helps maintain phospholipid asymmetry in cell membranes. ${ }^{38}$ Recently, in non-small cell lung cancer, ATP8A1 was found to be a novel direct target of miR-140-3p, ${ }^{39} \mathrm{a}$ small non-coding RNA molecule known to regulate gene expression, and that may contribute substantially to airway epithelium abnormalities. $^{40}$ Moreover, exposure of rats to cigarette smoke causes extensive alterations in miRNA expression of the miR-140 family in the lung. ${ }^{41}$ The $A B C A 1$ gene encodes a transport protein known to participate to the maintenance of lung lipid homeostasis by interacting with the apolipoprotein A-I (apoA-I), and which expression and function are affected by smoking. ${ }^{42}$ The critical role of ABCA1 in lung inflammation was evidenced from murine knockout models ${ }^{20}$ and a recent review reported that the apoA-I/ ABCA1 pathway was involved in the modulation of the function of airway structural cells, and associated with neutrophilic airway inflammation and airway hyper-responsiveness. ${ }^{43}$ Furthermore, rs17448506 located in ATP8A1 and rs2253304 in ABCA1 are both intronic variants, and map near regulatory elements, and TF-binding sites include that of NF- $\mathrm{B}$, an important participant in a broad spectrum of inflammatory networks that regulate cytokine activity in airway pathology. ${ }^{44}$ Lastly, tobacco smoke pollution and soot have been reported to modify the expression of ATP8A1 and $A B C A 1$ mRNA.

Interestingly, some of the previous genes detected to interact with ETS in BHR belong to or interact experimentally with genes belonging to the 'ATPase activity' or 'ATP binding' pathways. Among them, the ADRB2 gene belongs to the 'ATPase activity' pathway. The $P C D H 1$ gene ${ }^{6}$ was shown to interact with $A B C A 2$ and ATF7IP genes, which both belong to 'ATP binding' and/or 'ATPase activity' pathways. Similarly the PACRG and the EPB41L3 genes ${ }^{12}$ were also shown to interact with numerous genes belonging to 'ATP binding' and/or 'ATPase activity' pathways. Overall, all these data suggest that ATP8A1 and ABCA1 may play a role in BHR in relationship with early tobacco smoke exposure.

In conclusion, the present study highlights that $\mathrm{G} \times \mathrm{E}$ interaction analyses under a pathway-based strategy allowed to identify promising candidate genes interacting with ETS exposure in BHR susceptibility. Further confirmation of the interaction of ATP8A1 and ABCA1 with ETS exposure as well as functional studies is needed to bring greater insight into the role of these genes in BHR. Our study suggests that the two pathways are promising to be further explored in the search of more effective 
therapies for inflammatory lung diseases, especially for BHR which is a feature and an important risk factor for asthma.

\section{Author affiliations}

${ }^{1}$ INSERM, UMR-946, Genetic Variation and Human Diseases Unit, Paris, France ${ }^{2}$ Sorbonne Paris Cité, Institut Universitaire d'Hématologie, Université Paris Diderot, Paris, France

${ }^{3}$ Département des Sciences Fondamentales, Université du Québec, Chicoutimi, Quebec, Canada

${ }^{4}$ Service d'Allergologie Pédiatrique, Centre de I'Asthme et des Allergies, Hôpital d'Enfants Armand-Trousseau (APHP), UPMC Paris 06, Paris, France

${ }^{5}$ Department of Human Genetics, McGill University and Genome Quebec's Innovation Centre, Montréal, Québec, Canada

${ }^{6}$ Aging and Chronic Diseases-Epidemiological and Public Health Approaches (VIMA), Inserm, U1168, Villejuif, France

7UMR-S 1168, Université de Versailles Saint-Quentin-en-Yvelines, Paris, France

Acknowledgements We thank Inserm, the French Ministry of Higher Education and Research, University Paris Diderot, for supporting our research and the EGEA cooperative group: Coordination: V Siroux (epidemiology, PI since 2013); FD (genetics); I Pin (clinical aspects); RN (biology); F Kauffmann (PI 1992-2012). Respiratory epidemiology: Inserm ex-U 700, Paris: M Korobaeff (Egea1), F Neukirch (Egea1); Inserm ex-U 707, Paris: I Annesi-Maesano (Egea1-2); Inserm ex-U 1018, Villejuif: F Kauffmann, MP Oryszczyn (Egea1-2); Inserm U 1168, Villejuif: N Le Moual, RN, R Varraso; Inserm U 1209 Grenoble:V Siroux. Genetics: Inserm ex-U 393, Paris: J Feingold; Inserm U 946, Paris: EB, FD, MHD; CNG, Evry: I Gut (now CNAG, Barcelona, Spain), ML (now Univ McGill, Montreal, Canada). Clinical centres: Grenoble: I Pin, C Pison; Lyon: D Ecochard (Egea1), F Gormand, Y Pacheco; Marseille: D Charpin (Egea1), D Vervloet (Egea1-2); Montpellier: J Bousquet; Paris Cochin: A Lockhart (Egea1), R Matran (now in Lille); Paris Necker: E Paty (Egea1-2), P Scheinmann (Egea 1-2); Paris-Trousseau: A Grimfeld (Egea1-2), JJ. Data and quality management: Inserm ex-U155 (Egea1): J Hochez; Inserm U 1168, Villejuif: N Le Moual; Inserm ex-U780: C Ravault (Egea1-2); Inserm ex-U794: N Chateigner (Egea1-2); Grenoble: J Quentin (Egea1-2). SLSJ: The author thanks all participants included in the SLSJ asthma familial collection. CL is the chairholder of the Canada Research Chair on Genetic Determinants in Asthma (http://www.chairs-chaires.gc.ca), the director of the Inflammation and Remodeling Strategic Group of the Respiratory Health Network of the FRQS (http://rsr.chus.qc.ca) and member of the AllerGen (http:// www.allergen-nce.ca/).

Contributors MHD and RN conducted the design. MHD and PMJ performed the data analysis. MHD and RN interpreted the findings and drafted the initial version of the manuscript. JJ, CL, ML, FD, EB and MHD contributed to the data acquisition. FD and $E B$ revised the manuscript and all authors provided final approval of the version to be published.

Funding The French EGEA study was partly funded by grants from the French National Agency for Research (ANR 05-SEST-020-02/05-9-97, ANR 06-CEBS, ANR-11-BSV1-027-GWIS-AM). Genotyping of the asthma-ascertained samples was supported by grants from the European Commission (018996), the French Ministry of Higher Education and Research. We also acknowledge Region Ile de France (DIMSEnT 2011) and Fondation pour la recherche Médicale (FRM 2013) for their support. The Canada Research Chair on Genetic Determinants of Asthma held by CL since 2005 allows the maintenance of the French Canadian study.

Competing interests None declared.

Patient consent Obtained.

Ethics approval Ethical approval was obtained from the relevant institutional review board committees (Cochin Port-Royal Hospital and Necker-Enfants Malades Hospital, Paris). The SLSJ local ethics committee approved the study.

Provenance and peer review Not commissioned; externally peer reviewed.

\section{REFERENCES}

1 Rage E, Siroux V, Le Moual N, et al. Re: are asymptomatic airway hyperresponsiveness and allergy risk factors for asthma? A longitudinal study. Eur Respir J 2009;33:218-9.

2 March ME, Sleiman PM, Hakonarson H. Genetic polymorphisms and associated susceptibility to asthma. Int J Gen Med 2013;6:253-65.

3 Wjst M, Sargurupremraj M, Arnold M. Genome-wide association studies in asthma: what they really told us about pathogenesis. Curr Opin Allergy Clin Immunol 2013:13:112-8.

4 Rava M, Ahmed I, Kogevinas M, et al. Genes interacting with occupational exposures to low molecular weight agents and irritants on adult-onset asthma in three European studies. Environ Health Perspect 2017;125:207-14.

5 Ehrlich RI, Du Toit D, Jordaan E, et al. Risk factors for childhood asthma and wheezing. Importance of maternal and household smoking. Am I Respir Crit Care Med 1996;154(3 Pt 1):681-8.
6 Koppelman GH, Meyers DA, Howard TD, et al. Identification of PCDH1 as a novel susceptibility gene for bronchial hyperresponsiveness. Am I Respir Crit Care Med 2009;180:929-35.

7 Reijmerink NE, Kerkhof M, Koppelman GH, et al. Smoke exposure interacts with ADAM33 polymorphisms in the development of lung function and hyperresponsiveness. Allergy 2009;64:898-904.

8 Bukvic BK, Blekic M, Simpson A, et al. Asthma severity, polymorphisms in 20p13 and their interaction with tobacco smoke exposure. Pediatr Allergy Immunol 2013;24:10-18.

9 Wang Z, Chen C, Niu T, et al. Association of asthma with beta(2)-adrenergic receptor gene polymorphism and cigarette smoking. Am J Respir Crit Care Med 2001;163:1404-9.

10 Bouzigon E, Corda E, Aschard $\mathrm{H}$, et al. Effect of $17 \mathrm{q} 21$ variants and smoking exposure in early-onset asthma. N Eng/ J Med 2008;359:1985-94.

11 Moffatt MF, Kabesch M, Liang L, et al. Genetic variants regulating ORMDL3 expression contribute to the risk of childhood asthma. Nature 2007;448:470-3.

12 Scholtens S, Postma DS, Moffatt MF, et al. Novel childhood asthma genes interact with in utero and early-life tobacco smoke exposure. J Allergy Clin Immunol 2014;133:885-8.

13 Dizier MH, Bouzigon E, Guilloud-Bataille M, et al. Evidence for gene x smoking exposure interactions in a genome-wide linkage screen of asthma and bronchial hyper-responsiveness in EGEA families. Eur J Hum Genet 2007;15:810-5.

14 Dizier MH, Nadif R, Margaritte-Jeannin P, et al. Interaction between the DNAH9 gene and early smoke exposure in bronchial hyperresponsiveness. Eur Respir J 2016;47:1072-81.

15 Sugier PE, Brossard M, Sarnowski C, et al. A novel role for ciliary function in atopy: ADGRV1 and DNAH5 interactions. J Allergy Clin Immunol 2018;141.

16 King SM. Axonemal dynein arms. Cold Spring Harb Perspect Biol 2016;8:a028100.

17 Roberts AJ, Kon T, Knight PJ, et al. Functions and mechanics of dynein motor proteins. Nat Rev Mol Cell Biol 2013;14:713-26.

18 Tilley AE, Walters MS, Shaykhiev R, et al. Cilia dysfunction in lung disease. Annu Rev Physiol 2015;77:379-406.

19 Idzko M, Hammad H, van Nimwegen M, et al. Extracellular ATP triggers and maintains asthmatic airway inflammation by activating dendritic cells. Nat Med 2007:13:913-9.

20 Chai $A B$, Ammit AJ, Gelissen IC. Examining the role of $A B C$ lipid transporters in pulmonary lipid homeostasis and inflammation. Respir Res 2017;18:41.

21 Houtmeyers E, Gosselink R, Gayan-Ramirez G, et al. Regulation of mucociliary clearance in health and disease. Eur Respir J 1999;13:1177-88.

22 Huynh TP, Mah V, Sampson VB, et al. Na,K-ATPase is a target of cigarette smoke and reduced expression predicts poor patient outcome of smokers with lung cancer. Am J Physiol Lung Cell Mol Physiol 2012;302:L1150-8.

23 Padmavathi $P$, Reddy VD, Maturu $P$, et al. Smoking-induced alterations in platelet membrane fluidity and $\mathrm{Na}(+) / \mathrm{K}(+)$-ATPase activity in chronic cigarette smokers. J Atheroscler Thromb 2010;17:619-27.

24 Horvath S, Xu X, Laird NM. The family based association test method: strategies for studying general genotype-phenotype associations. Eur J Hum Genet 2001;9:301-6.

25 Umbach DM, Weinberg CR. The use of case-parent triads to study joint effects of genotype and exposure. Am J Hum Genet 2000;66:251-61.

26 Kauffmann F, Dizier MH, Pin I, et al. Epidemiological study of the genetics and environment of asthma, bronchial hyperresponsiveness, and atopy: phenotype issues. Am J Respir Crit Care Med 1997;156(4 Pt 2):S123-9.

27 Laprise C. The Saguenay-Lac-Saint-Jean asthma familial collection: the genetics of asthma in a young founder population. Genes Immun 2014;15:247-55.

28 Moffatt MF, Gut IG, Demenais F, et al. A large-scale, consortium-based genomewide association study of asthma. N Eng/ J Med 2010;363:1211-21.

29 Lake SL, Blacker D, Laird NM. Family-based tests of association in the presence of linkage. Am J Hum Genet 2000;67:1515-25.

30 Dizier MH, Margaritte-Jeannin P, Madore AM, et al. The nuclear factor I/A (NFIA) gene is associated with the asthma plus rhinitis phenotype. J Allergy Clin Immunol 2014;134:576-82.

31 Li J, Ji L. Adjusting multiple testing in multilocus analyses using the eigenvalues of a correlation matrix. Heredity 2005;95:221-7.

32 Liu JZ, McRae AF, Nyholt DR, et al. A versatile gene-based test for genome-wide association studies. Am J Hum Genet 2010;87:139-45.

33 Gibson G. Human genetics. GTEx detects genetic effects. Science 2015;348:640-1.

34 Davis AP, Grondin CJ, Lennon-Hopkins K, et al. The comparative toxicogenomics Database's 10th year anniversary: update 2015. Nucleic Acids Res 2015;43:D914-20.

35 Blekic M, Kljaic Bukvic B, Aberle N, et al. 17q12-21 and asthma: interactions with early-life environmental exposures. Ann Allergy Asthma Immunol 2013;110:347-53.

36 Allen L, Williams J, Townsend N, et al. Socioeconomic status and non-communicable disease behavioural risk factors in low-income and lower-middle-income countries: a systematic review. Lancet Glob Health 2017;5:e277-e89.

37 Kuntz B, Lampert T. Social disparities in parental smoking and young children's exposure to secondhand smoke at home: a time-trend analysis of repeated crosssectional data from the German KiGGS study between 2003-2006 and 2009-2012. BMC Public Health 2016;16:485. 
38 Sobocki T, Jayman F, Sobocka MB, et al. Isolation, sequencing, and functional analysis of the TATA-less murine ATPase II promoter and structural analysis of the ATPase II gene. Biochim Biophys Acta 2007;1769:61-75.

39 Dong W, Yao C, Teng X, et al. MiR-140-3p suppressed cell growth and invasion by downregulating the expression of ATP8A1 in non-small cell lung cancer. Tumour Biol 2016;37:2973-85.

40 Moheimani F, Hsu AC, Reid AT, et al. The genetic and epigenetic landscapes of the epithelium in asthma. Respir Res 2016;17:119.
41 Izzotti A, Calin GA, Arrigo P, et al. Downregulation of microRNA expression in the lungs of rats exposed to cigarette smoke. Faseb J 2009;23:806-12.

42 Jubinville É, Talbot M, Bérubé JC, et al. Interplay between cigarette smoking and pulmonary reverse lipid transport. Eur Respir J 2017;50:1700681.

43 Yao X, Gordon EM, Barochia AV, et al. The A's Have It: developing apolipoprotein A-I mimetic peptides into a novel treatment for asthma. Chest 2016;150:283-8.

44 Schuliga M. NF-kappaB signaling in chronic inflammatory airway disease. Biomolecules 2015;5:1266-83. 